\title{
FAMILIAL SUPRAVALVAR AORTIC STENOSIS
}

\author{
BY \\ W. F. W. E. LOGAN, E. WYN JONES, E. WALKER, N. COULSHED, AND \\ E. J. EPSTEIN \\ From the Liverpool Regional Cardiac Centre, Sefton General Hospital, Liverpool 15
}

Received August 4, 1964

Though supravalvar aortic stenosis is uncommon and fewer than 80 cases have been described, nevertheless, a clinical picture is gradually emerging based on observations from many different units.

This paper is concerned with the diagnosis of supravalvar stenosis in six patients in three generations of a family. The findings are presented to show that supravalvar stenosis may be clinically distinguished from other causes of left ventricular outflow obstruction.

\section{CASE REPORTS}

Case 1. (Fig. 1: III.20.) A. McA., aged 23, at the age of 9 had been found to have a basal systolic murmur. Over the next 14 years he was examined at regular intervals and full investigations were undertaken when he began to complain of slight effort dyspnœa and præcordial pain on exertion.

On examination, he was of normal physique and intelligence. His facial appearance was normal. The only abnormalities detected were in the cardiovascular system.

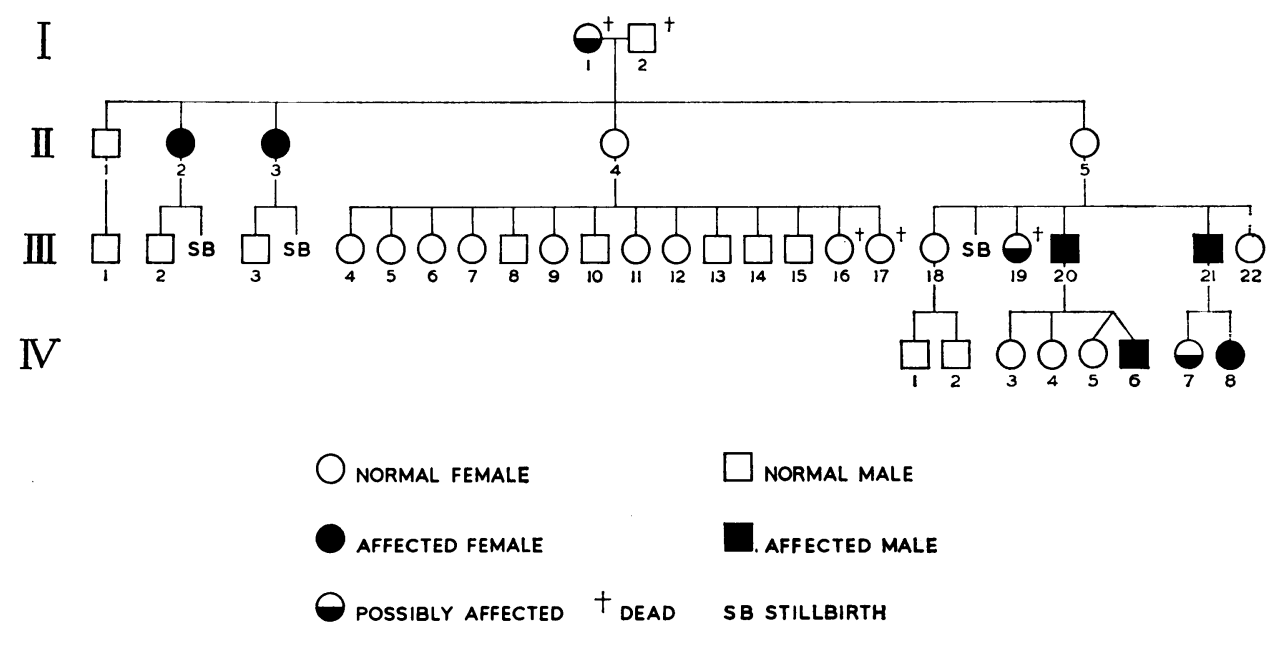

Fig. 1.-Family pedigree. Case I.1. This woman died suddenly aged 36. Death was certified as due to valvular heart disease. II.2, II.3, III.20, III.21, IV.6, and IV.8, are described in detail in the text. III.19 died aged 1 month, from congenital heart disease, said to be a patent foramen ovale. IV.7, a 2-year-old girl, has a soft basal systolic murmur without other abnormality. No details are available regarding the stillborn infants. Many other members of this family have been examined and found normal. 


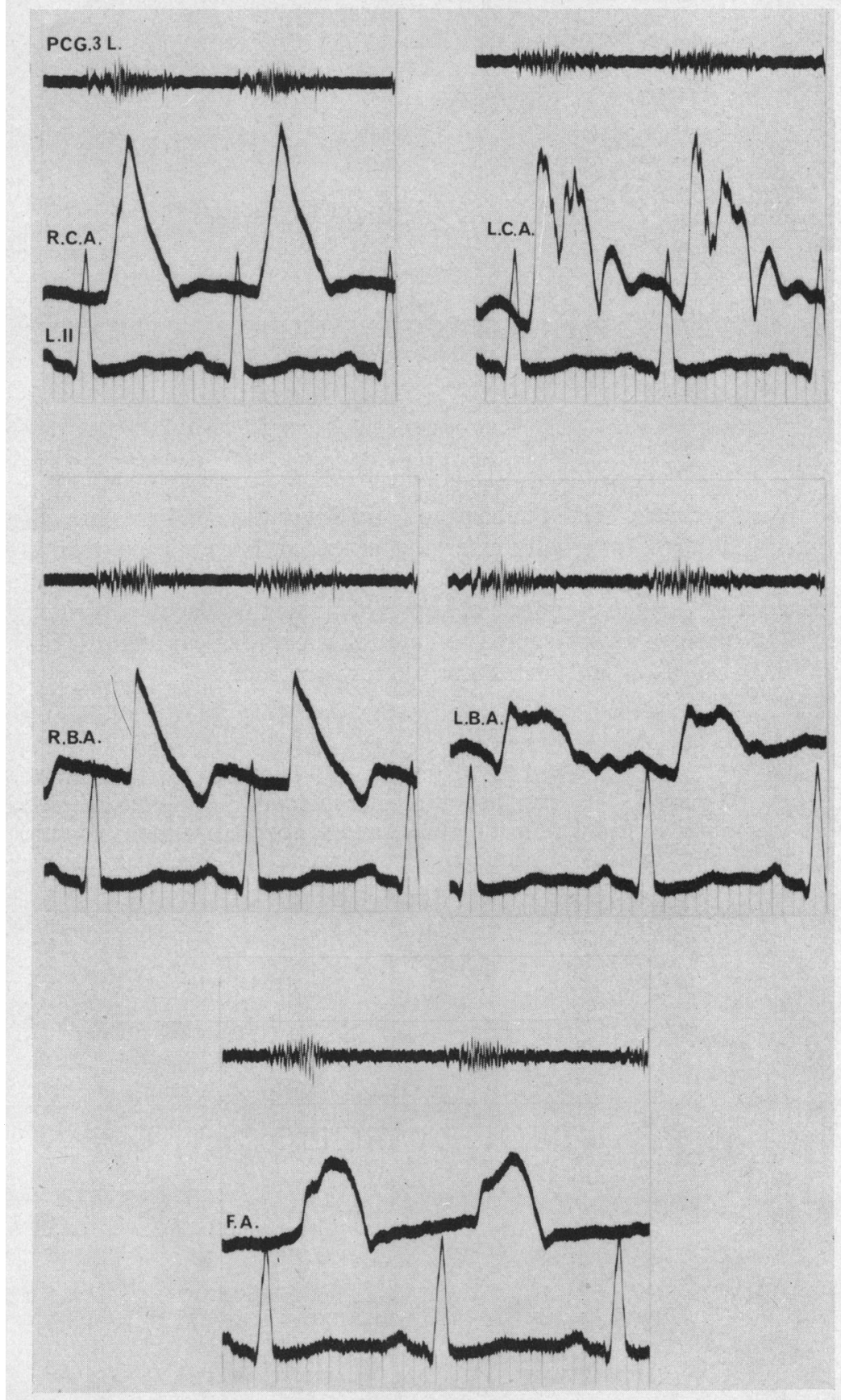

FIG. 2.-The same abbreviations are used in succeeding figures. PCG 3 L., medium frequency phonocardiogram third left intercostal space close to the sternum; R.C.A., right carotid artery; L.C.A., left carotid artery; R.B.A., right brachial artery; L.B.A., left brachial artery; F.A., femoral artery; L.II, electrocardiogram standard lead II. The time markers are at $40 \mathrm{msec}$. intervals. Recordings have been made at a paper speed of $50 \mathrm{~mm}$. a second.

This figure shows the pulse tracings obtained from Case 1, A. McA., who had mild supravalvar stenosis. The difference between the two sides is striking. The right carotid and brachial arteries show a sharply peaked pulse form, whereas on the left the pulse form is clearly bisferiens in character. The peak of the femoral pulse is delayed. The PCG shows the mid-systolic murmur and clearly visible second sound. 
TABLE

HaMODYNAMIC DATA

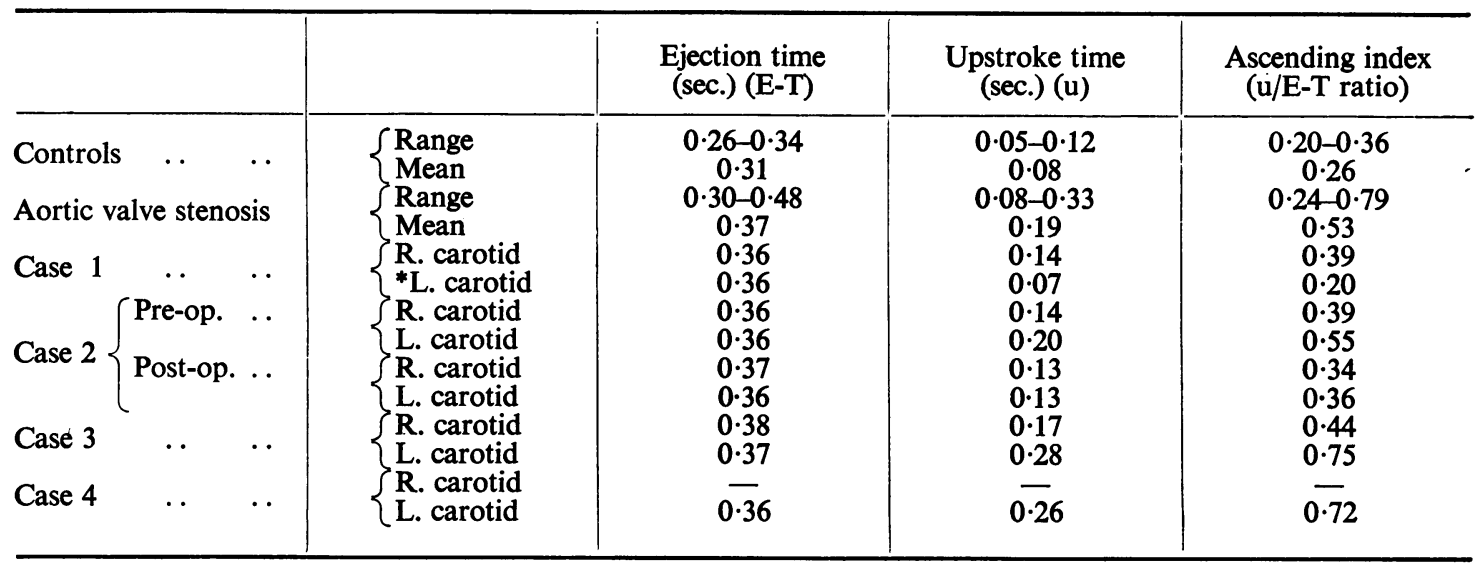

Note: All times given in seconds and corrected for heart rate using the Bazett formula.

* This pulse had a bisferiens wave form.

There was visibly excessive pulsation of the right carotid artery, but the left was normal. A marked inequality between the radial pulses was palpable and the brachial blood pressure on the right was 140/60 and on the left $105 / 80 \mathrm{~mm}$. Hg. The femoral pulses felt normal and there was no delay in their appearance (Fig. 2 and the Table). The cardiac rhythm was regular, and the apex beat pulsation was normal in character and position. A loud mid-systolic murmur could be heard over a wide area, but best in the first right intercostal space and suprasternal notch, where it was accompanied by a thrill. There was no systolic click nor was there a diastolic murmur. The pulmonary and aortic components of the second sound were normal. The electrocardiogram showed slight left ventricular hypertrophy. Radiologically there were no abnormal features.

Right heart catheterization revealed no abnormality. Using a transseptal technique to enter the left atrium and left ventricle (Cope, 1959; Ross, Braunwald, and Morrow, 1960; Brockenbrough and Braunwald, 1960), pressures were recorded which demonstrated a peak systolic gradient of $25 \mathrm{~mm}$. Hg between the left ventricle and the right brachial artery.

Left ventricular angiography was performed, and the angiogram clearly demonstrated supravalvar narrowing of the aorta (Fig. 3). There was also slight "kinking" of the aorta between the innominate and the left common carotid arteries. In view of the minor hæmodynamic abnormality, an operation was not thought necessary.

Case 2. (Fig. 1: III.21.) K. McA., aged 18, had been cyanosed for some time after birth, and congenital heart disease was suspected. The first detailed clinical findings were not recorded until he was 5 years old when he was found to have a basal systolic murmur. There was no cyanosis or clubbing and no evidence of coarctation of the aorta. He was seen at regular intervals and when he began to complain of dyspnoea and anginal-type pain on exertion he was investigated in this Unit.

The patient was of normal physique, facial appearance, and intelligence, the only abnormalities detected being in the cardiovascular system. Very excessive pulsation of the right carotid artery was present and had been noted for several years. The arm pulses were unequal and the right brachial blood pressure was 160/70 and the left $110 / 70 \mathrm{~mm}$. Hg. The femoral pulses were normal and not delayed (Fig. 4 and the Table). The apex beat was normal in site and slightly thrusting in character. A systolic thrill was felt in the suprasternal notch and over the right carotid artery. A mid-systolic murmur was audible over a wide area but best heard in the first right intercostal space close to the sternum, in the suprasternal notch, and over the right carotid artery. There was no diastolic murmur and no systolic click. The aortic component of the second sound could be heard and was normal. The electrocardiogram showed marked left ventricular hypertrophy with deeply inverted $T$ waves over the left ventricle. There was no significant radiological abnormality. Right and left heart catheterizations revealed a peak systolic gradient of $95 \mathrm{~mm}$. $\mathbf{H g}$ measured between the left ventricle and right brachial artery. In addition, the systolic pressure in the right brachial artery was $25 \mathrm{~mm}$. $\mathrm{Hg}$ greater than in the left brachial artery. Left ventricular angiography 


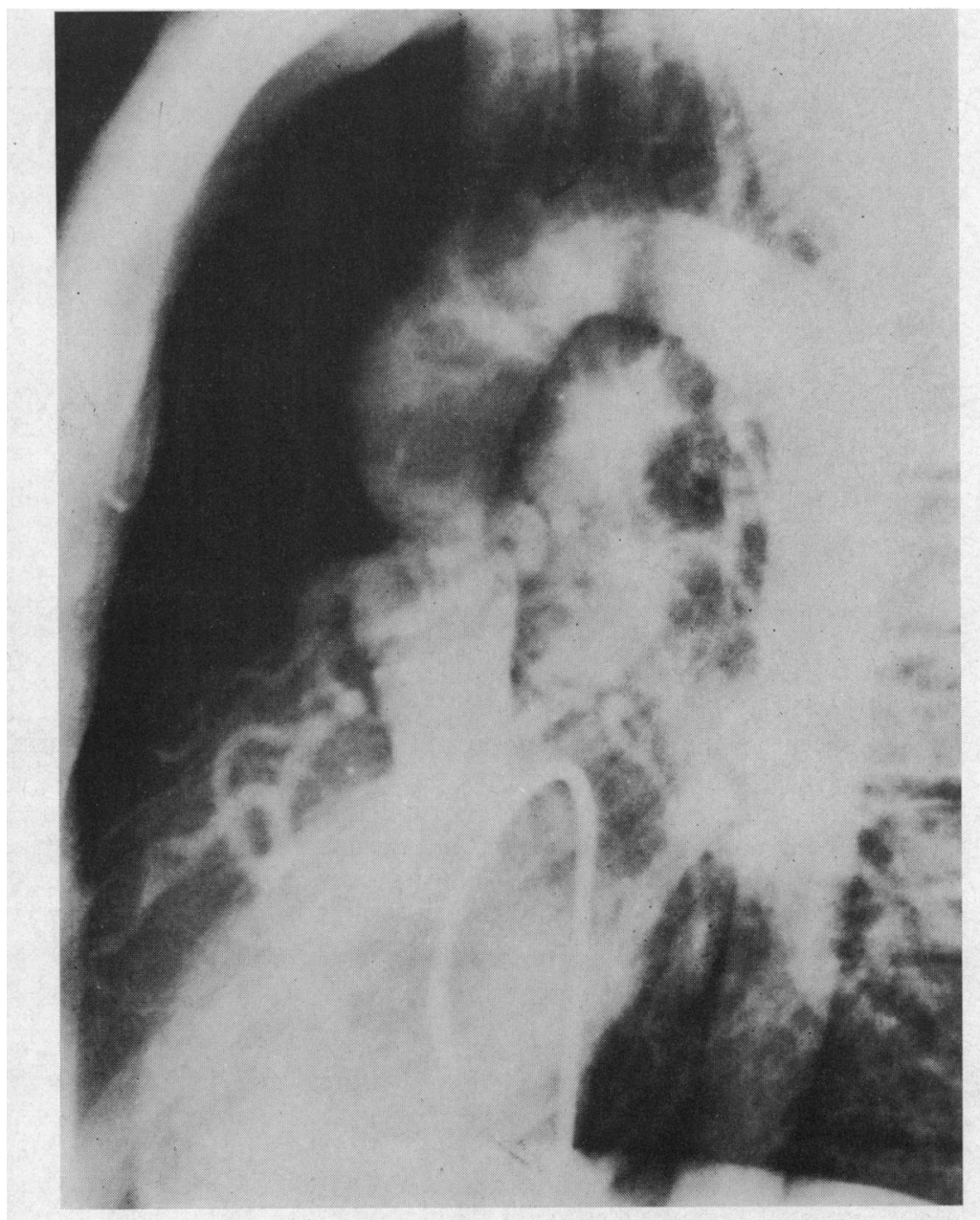

FIG. 3.-Case 1, A. McA. Left ventricular angiocardiogram, left lateral position. The supravalvar narrowing of the aorta is demonstrated as are the large coronary arteries. There appears to be slight post-stenotic dilatation of the aorta. The peak systolic gradient across the supravalvar stenosis was $25 \mathrm{~mm}$. $\mathrm{Hg}$.

demonstrated a supravalvar stenosis and a further narrowing of the aorta at the level of the ligamentum arteriosum suggestive of a minor degree of coarctation (Fig. 5).

Because of these findings, operation was advised to relieve the supravalvar obstruction. This was successfully performed by Mr. L. J. Temple by the insertion of a teflon gusset. There was no evidence of a patent ductus arteriosus, but the aorta was kinked and slightly narrowed at the ligamentum arteriosum. The aortic valve was normal and the coronary arteries were large and tortuous but otherwise normal.

Post-operatively he has done well and is symptom-free. The deep $T$ wave inversion over the left ventricle has regressed and the pulses in both left and right arms are similar. There is no longer excessive pulsation of the right carotid artery (Fig. 6). The blood pressure in the right arm is 130/60 and in the left $105 / 60 \mathrm{~mm}$. Hg.

Case 3. (Fig. 1: II.2.) V.M., aged 43, had a heart lesion which was discovered at the age of 7 years; there was no history of a rheumatic illness. She had been breathless for many years due to bronchial asthma. On examination, though overweight, she was of normal appearance and intelligence. The only abnormal findings were in the cardiovascular system. There was excessive pulsation of the right carotid artery; the right brachial arterial pulse was collapsing in quality, whereas the left was of poor volume; and 

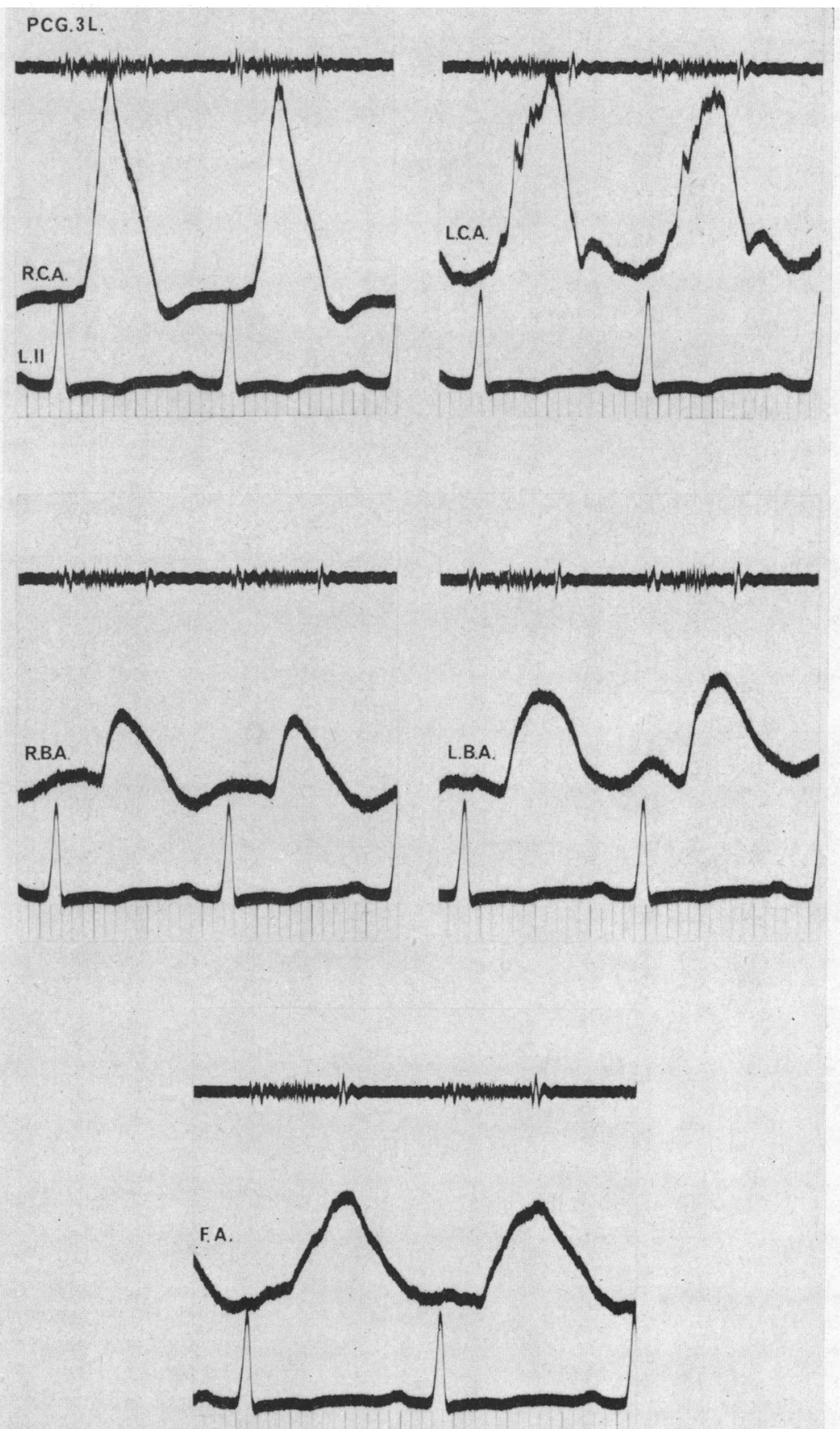

Fig. 4.-Case 2, K. McA. The pulse form of the right carotid artery shows a steep rise and fall and the right brachial artery pulse is similar. The pulse in the left carotid artery and in the left brachial artery is anacrotic. The peak of the femoral pulse is delayed. The PCG shows a midsystolic murmur and a well-defined aortic second sound. 


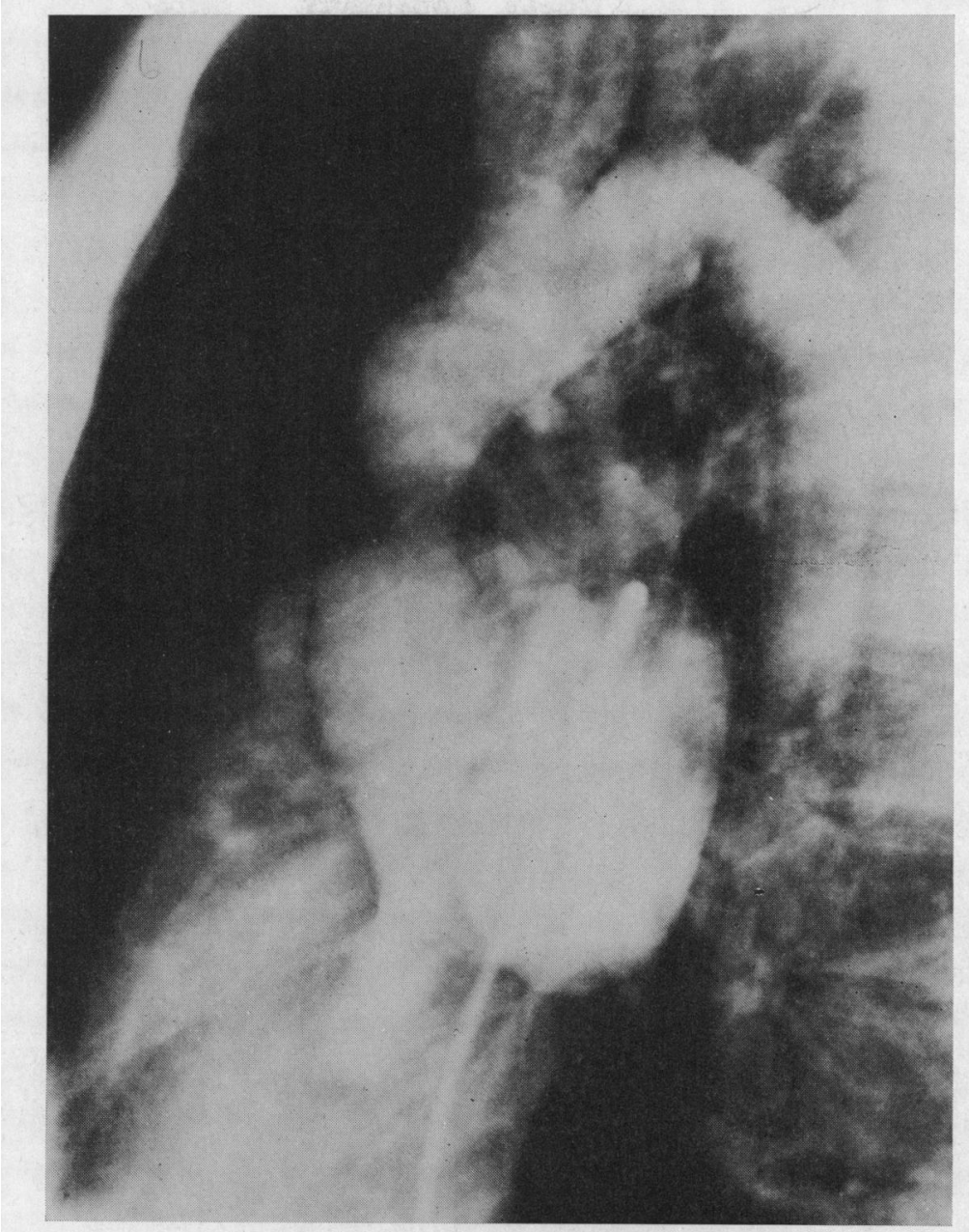

FIG. 5.-Case 2, K. McA. Left ventricular angiocardiogram, left lateral position. The supravalvar stenosis and very large coronary arteries can be seen. Kinking of the aorta distal to the origin of the subclavian artery is clearly visible. The peak systolic gradient across the supravalvar stenosis was $95 \mathrm{~mm}$. $\mathrm{Hg}$ in this patient.

the blood pressure in the right arm was $130 / 60$ and in the left arm 100/80 mm. Hg. The apex beat was in the 5th interspace 4 in. $(10 \mathrm{~cm}$.) from the midline. There was a mid-systolic murmur and thrill maximal at the base and radiating into both carotid arteries. The second sound was normal. There was no systolic click nor was there a diastolic murmur.

The electrocardiogram showed marked left ventricular hypertrophy as did the chest films. There was no aortic valve calcification. The pulse tracings with phonocardiograms are shown in Fig. 7 and the Table. There was clear evidence of severe obstruction and in view of the similarity to Cases 1 and 2, a clinical diagnosis of supravalvar aortic stenosis was made. The patient refused further investigation.

Case 4. (Fig. 1: II.3.) E.C., aged 40, had a heart lesion that had been noted at birth, and she had been troubled with progressive effort breathlessness and angina for several years; she is at present moderately incapacitated.

On examination, she was of normal facial appearance and intelligence but a little overweight. Pulsation of the right carotid artery was much more vigorous than that of the left and the brachial pulses were unequal. The blood pressure in the right arm was $130 / 65 \mathrm{~mm}$. $\mathrm{Hg}$, and the pulse collapsing; in the left arm the pulse was anacrotic, and the blood pressure was $120 / 90 \mathrm{~mm}$. Hg. The phonocardiogram and left 


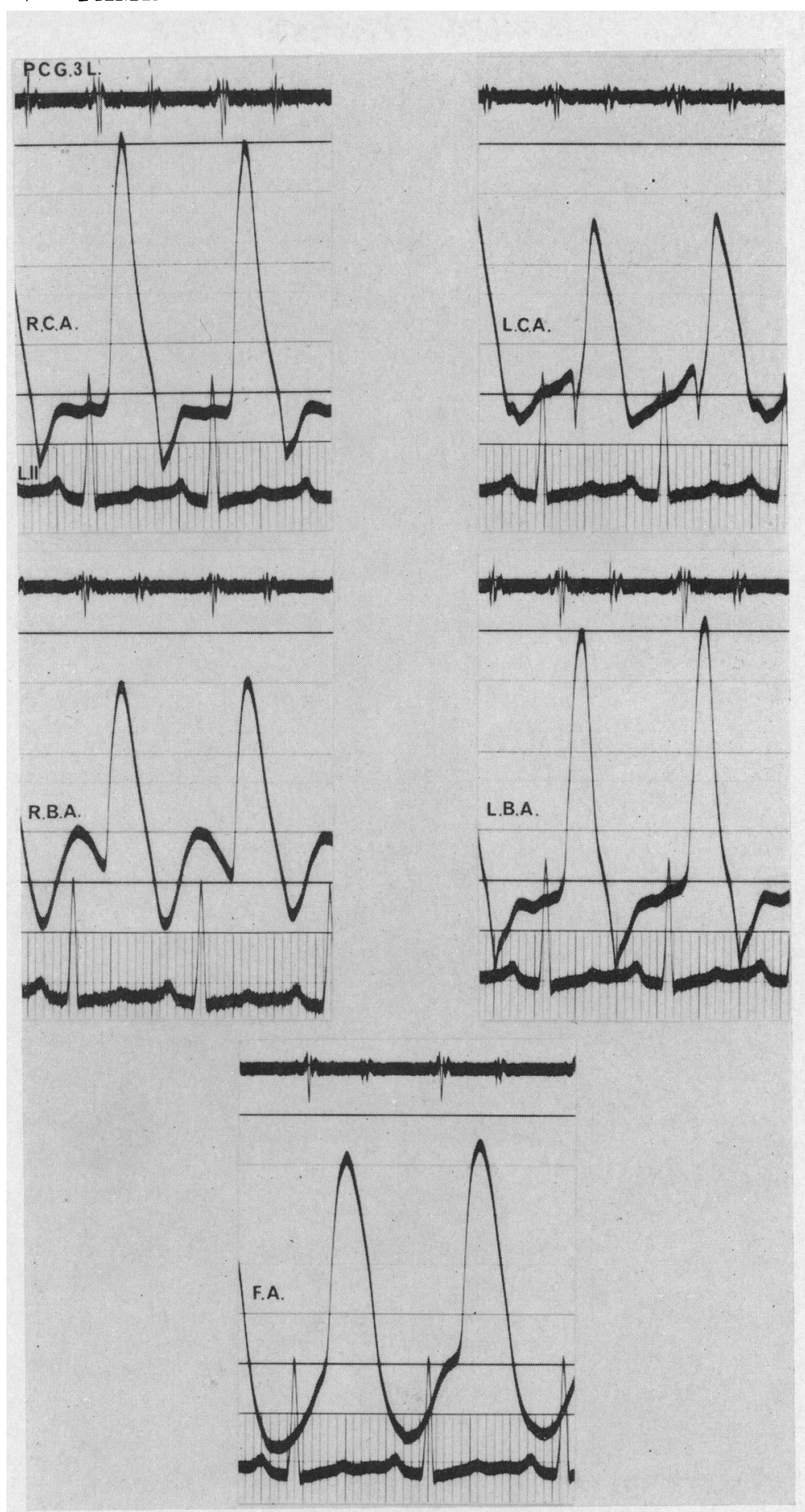

Fig. 6.-Case 2, K. McA. Post-operative pulse tracings. There is no delay in the upstroke of the left carotid and left brachial pulse tracings which now resemble the pulses on the right side. The femoral pulse wave now has a normal appearance. The systolic murmur has virtually disappeared. 


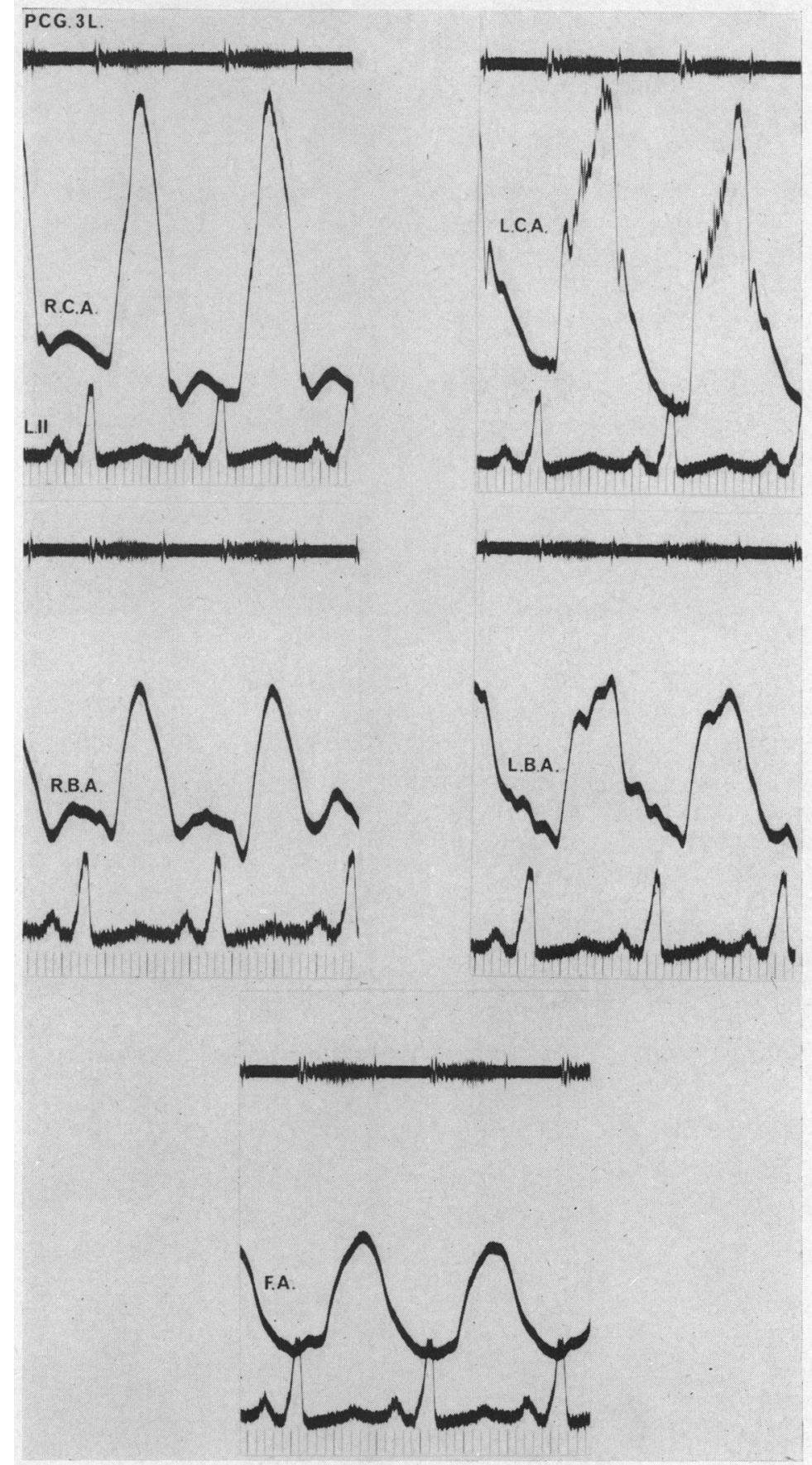

Fig. 7.-Case 3, V.M. The right carotid and right brachial pulse tracings show a steep upstroke compared to anacrotic pulse forms on the left side. The femoral artery pulse is also anacrotic: The PCG shows a mid-systolic murmur and well-defined aortic second sound. 


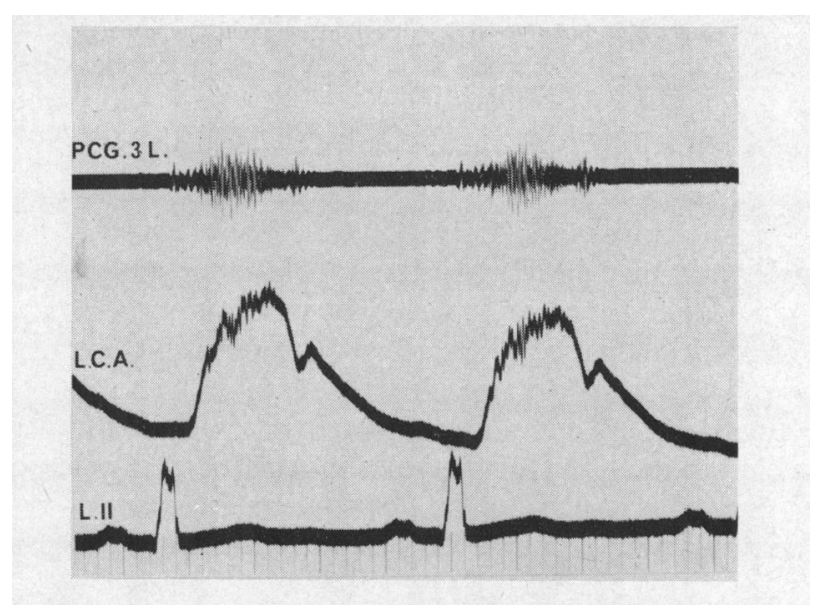

FIG. 8.-Case 4, E.C. An anacrotic left carotid artery pulse is present. The PCG shows the mid-systolic murmur and well-defined aortic second sound.

carotid pulse tracing are shown in Fig. 8. The cardiac impulse was not localized but a systolic thrill was palpable at the base, in the suprasternal notch, and over both carotid arteries. An associated mid-systolic murmur was maximal in the suprasternal notch. The aortic and pulmonary second sounds were normal and there was no systolic click nor was there a diastolic murmur. The electrocardiogram showed marked left ventricular hypertrophy which was also evident on the chest film. There was no visible aortic valve calcification.

The clinical diagnosis was of left ventricular obstruction due to supravalvar stenosis. The patient refused further investigation.

Case 5. (Fig. 1: IV.6.) A. McA., aged 2 years, had a heart murmur detected shortly after birth. There were no obvious external congenital defects and there had not been any cyanosis. The arm and carotid pulses were unequal, those on the right being more prominent. The blood pressure in the right arm was $180 / 0$ and in the left arm $120 / 70 \mathrm{~mm}$. Hg. The femoral pulses were not delayed. A systolic thrill was palpable over both carotid arteries and in the suprasternal notch with an associated loud mid-systolic murmur. The second sound was normally split and there was no systolic click nor was there any diastolic murmur. The electrocardiogram and chest films were normal.

The phonocardiogram showed an ejection type of systolic murmur. No further investigations have so far been performed. This patient has a normal twin sister. The clinical diagnosis was of supravalvar aortic stenosis.

Case 6. (Fig. 1: IV. 8.) J. McA., age 2 years, was cyanosed at birth, and systolic and diastolic murmurs were heard at the base. The possibility of a patent ductus arteriosus was considered. The cyanosis cleared within a few weeks and the infant has since been well and symptom free.

On examination, there were epicanthic folds present without any other facial abnormality. The arm pulses were equal and the blood pressure in the right arm was $95 / 65$ and in the left leg $100 / 65 \mathrm{~mm}$. $\mathrm{Hg}$. A prominent aortic systolic thrill and mid-systolic murmur were present in the suprasternal notch over both carotid arteries, more readily detected on the right than the left, and also faintly at the left sternal edge. The aortic and pulmonary second sounds were normal and there was no systolic click nor was there any diastolic murmur. The femoral pulses were normal.

The electrocardiogram showed slight prominence of the left ventricle. The chest film was normal. Phonocardiography showed the presence of a mid-systolic murmur. The clinical diagnosis was of probable supravalvar aortic stenosis.

\section{Discussion}

Though there have been occasional necropsy reports of supravalvar aortic stenosis (Archer, 1878; Mencarelli, 1930; Lev, 1953; Cheu, Fiese, and Hatayama, 1957; Burry, 1958), attention was initially drawn to the importance of distinguishing it from valvar aortic stenosis by Denie and Ver- 
heugt (1958). A review of published descriptions of supravalvar stenosis reveals several features, well illustrated by the cases described here, that may enable the diagnosis to be made from a clinical examination.

Marked pulsation of the right carotid artery and inequality of the arm pulses were present in 5 of 6 patients of the present series. This had previously been noted by Morrow et al. (1959); Hancock (1961); Williams, Barratt-Boyes, and Lowe (1961); Wooley et al. (1963); Beuren, Apitz, and Harmjanz (1962); Franch and Oran (1963); Lurie and Mandelbaum (1963). Associated with the pulse inequality either the systolic blood pressure or the pulse pressure has been greater in the right than the left arm. In 4 of the 6 patients described here indirect carotid, brachial, and femoral pulse forms have been recorded with a piezo-electric microphone to demonstrate graphically the differences between the two sides. Representative tracings are shown in Fig. 2, 4, 7, and 8.

There are three possible explanations for the pulse inequalities. First, a coarctation of the aorta between the origins of the innominate and left carotid arteries could produce prominent right carotid and right brachial pulses and smaller left carotid and left brachial pulses. Cases 1 and 2 of this series, where angiography has been done, show narrowing or kinking of the aorta, but it is distal to the origins of the left carotid and subclavian arteries.

An alternative anatomical explanation would be an abnormality at the origin of the main vessels from the aortic arch. Franch and Oran (1963) demonstrated a peak systolic gradient between the arch of the aorta and left carotid artery in a patient with aortographic evidence of narrowing of the orifices of the left carotid and left subclavian arteries. In another patient with supravalvar aortic stenosis and asymmetrical pulses they found at necropsy intimal and medial thickening of the ascending aorta which narrowed the orifices of the main vessels arising from the arch. In Case 2 of this series there is slight narrowing of the origin of the left subclavian artery visible on the angiogram.

A third possible explanation for the pulse inequalities in supravalvar stenosis is that the left ventricular outflow is directed by the stenosis in a "jet" towards the innominate artery producing abnormal right brachial and carotid pulses. A patient described by Morrow et al. (1959) developed a saccular aneurysm close to the origin of the innominate artery, which could have been related to the trauma of jet impact. Further evidence of the presence of a "jet" can be seen on angiograms.

In patients with supravalvar aortic stenosis more than one factor may be responsible for the production of the pulse wave inequalities which have frequently been observed. A study of the pulse waves as described by Epstein and Coulshed (1964) provided useful information. The upstroke time $(\mathrm{u})$, the ejection time (E-T), and the ascending index (u/E-T ratio) were measured. The right-sided pulses showed a steep ascent, a short upstroke time, and a low ascending index. By contrast the left-sided pulses were anacrotic with prolongation of both the upstroke time and the ejection time and a high ascending index (Table). From this Table it can be seen that Cases 2, 3, and 4 have an ascending index on the left side that is compatible with severe aortic obstruction. Unfortunately representative tracings of the right carotid and right brachial arteries could not be obtained from Case 4.

Localized narrowing of the origins of the left carotid and subclavian arteries could be responsible for anacrotic left carotid and left brachial pulse forms. However, the femoral pulses, recorded in three of our patients, were also anacrotic and resembled the left arm and neck pulses (Fig. 2, 4, and 7). In the absence of coarctation of the aorta an anacrotic femoral pulse reflects an anacrotic pulse form in the central aorta distal to the supravalvar stenosis. Central aortic catheter tracings in a number of published case reports confirm an anacrotic pulse beyond the stenosis (Denie and Verheugt, 1958; Morrow et al., 1959; Dotter et al., 1961; Hancock, 1961). These findings support the hypothesis of a jet of blood directed towards the innominate artery producing an alteration in the basic aortic pulse contour. Franch and Oran (1963) described a patient with a higher systolic pressure in the innominate artery than in the aorta apparently due to this phenomenon. In aortic valve stenosis it is unusual in adults to find any significant difference between the pulses on the two sides. 
In addition to the abnormal features in the carotid and brachial pulses the mid-systolic murmur and thrill appear to be situated at a higher site than in aortic valve stenosis. They were especially prominent in the first right intercostal space and the suprasternal notch radiating into both carotids, especially the right. No patient in this series had a systolic click or aortic diastolic murmur. The aortic second sound was audible in all cases. An aortic diastolic murmur has been present in some of the reported cases; its presence, therefore, does not exclude a supravalvar stenosis (Denie and Verheugt, 1958; Morrow et al., 1959; Wooley et al., 1963). Hancock (1961) has described the only patient in whom a systolic click has been recorded.

A history of cyanosis for several weeks after birth in a patient with signs of aortic obstruction may be helpful. This history was given by Case 2 (III.21) and Case 6 (IV.8). The latter patient had evidence of a patent ductus arteriosus in infancy. The cyanosis cleared within a few weeks but the patient, now 2 years old, has a loud basal systolic murmur and features suggestive of supravalvar stenosis. It is possible that the aortic obstruction produces hæmodynamic effects that alter the mechanism of closure of the ductus. Brody (1942) described a patient with an obstructing band across the aortic root in whom the ductus had remained patent for much longer than normal. A case reported by Morrow et al. (1959) had a patent ductus arteriosus.

Dilatation of the ascending aorta is not found in supravalvar aortic stenosis, and the vascular pedicle has been described as unusually narrow (Dotter et al., 1961; Beuren et al., 1962). A dilated ascending aorta in a patient with the clinical signs of aortic stenosis makes the diagnosis of supravalvar stenosis unlikely.

One of the most striking features sometimes found in association with supravalvar stenosis; but not present in the cases reported here, is a peculiar facial appearance first described by Williams et al. (1961). They described 4 patients all mentally retarded, and the close facial resemblance of the patients to one another was remarkable. In addition, these patients had blue irises and tortuous retinal vessels. Similar findings to those of Williams have been reported by Beuren et al. (1962); Palmer et al. (1963); Joseph, Polani, and Gold (1963); and Black and Bonham Carter (1963). Of the patients in whom supravalvar stenosis was associated with subnormal intelligence and abnormal facies, one described by Palmer et al. (1963) and Palmer (1963) had abnormal chromosomes. This patient exhibited mosaicism and had an extra group 19-20 chromosome in most of his cells. Two other patients in Palmer's series who had abnormal facies and low intelligence had normal chromosomes. De Grouchy and Emerit (1963) found normal chromosomes in two patients of this type and Eberle and Beuren (1963) found normal chromosomes in three further patients with supravalvar stenosis, abnormal facies, and low intelligence.

Recently Black and Bonham Carter (1963) described 5 patients who appeared to have aortic stenosis associated with abnormal facies and mental retardation. These patients were previously thought to have the severe type of hypercalcæmia of infancy. Full cardiological studies in one patient showed supravalvar aortic stenosis. In the other 4 the exact site of outflow obstruction was not determined. Chromosome studies were not carried out. However, Joseph et al. (1963) reported normal chromosomes in a girl of 10 who had severe infantile hypercalcæmia and now has moderate aortic stenosis (site undetermined) with abnormal facies and mental retardation. The resemblance of the patients described by Williams et al. (1961) to those described by Black and Bonham Carter (1963) is striking and some cases of supravalvar stenosis in mentally retarded patients who have abnormal facies may be associated with the severe type of hypercalcæmia of infancy. Fletcher (1957) and Rashkind, Golinko, and Arcasoy (1961) described abnormal aortic valves in patients with the severe type of hypercalcæmia, and, therefore, some of the patients with this condition may have aortic valve stenosis rather than supravalvar stenosis.

In 10 patients with supravalvar aortic stenosis associated with a "peculiar" facial appearance and mental retardation, multiple peripheral pulmonary artery stenoses have been found by Beuren et al. (1964). Of the 3 patients having chromosome studies the karyotypes were normal. Two of our patients (Cases 1 and 2), in whom right-sided catheter studies were performed, showed no pulmonary artery gradients. 
A familial occurrence of supravalvar aortic stenosis was first reported by Sissman et al. (1959) in a 70-year-old woman and her grandson. Both the mother and a sister of this woman had congenital heart disease but no further information was available. Wooley et al. $(1961,1963)$ described two further affected families in their series of patients: a mother and son in one family and a brother and sister in another. Franch and Oran (1963) reported an affected brother and sister and Palmer et al. (1963) described three affected families. In two of these families, sibs were affected and in the third family both a sib and a child of the propositus had supravalvar stenosis.

The family reported here (Fig. 1) illustrates the occurrence of supravalvar stenosis in three successive generations and probably in a fourth generation (I.1). As far as can be ascertained, there are no consanguineous marriages in the family. Both sexes are affected as in the other reported families. In this family two members have been shown to have supravalvar stenosis. A further four members are considered to have supravalvar stenosis on clinical grounds. Three other members of the family about whom only limited information is available have been classified as possible additional cases of supravalvar aortic stenosis. Chromosome studies in one patient (III.21) were normal. The pedigree suggests a dominant Mendelian inheritance, but the ratio of affected to normal individuals is less than the expected $1: 1$ so there is incomplete penetrance. If there are two congenital heart lesions in a family the malformations are more likely to be concordant than discordant (Lamy, de Grouchy, and Schweisguth, 1957). III.19 died in infancy with congenital heart disease, said to be a "patent foramen ovale", but complete data were not available.

A review of earlier reports shows that there are several anatomical varieties of supravalvar aortic stenosis. Most frequently the lesion is a discrete waist-like narrowing above the aortic valve cusps. On occasion there may be narrowing of a segment of the ascending aorta, or more rarely the entire ascending aorta and arch may be hypoplastic. A few cases of obstructing supravalvar membranes and bands have been reported. There was no obvious association between the anatomical varieties of supravalvar aortic stenosis and the clinical types.

We propose the following clinical classification. (1) Non-familial-sporadic: normal facial appearance and intelligence. (2) Familial: normal facial appearance and intelligence. (3) Syndrome of abnormal facial appearance and mental retardation: (a) normal chromosomes and occasional association with severe infantile hypercalcæmia or multiple peripheral pulmonary artery stenoses; and (b) abnormal chromosomes.

\section{SUMMARY}

Six patients with supravalvar aortic stenosis have been described who are all members of the same family. The disorder was found in three generations and possibly in a fourth generation. Chromosome studies in one patient were normal. The pedigree shows that the supravalvar stenosis was inherited as a Mendelian dominant.

The diagnosis is suggested by certain clinical features. The principal ones are a history of cyanosis in infancy, inequality between the right and left arm and neck pulses, and an unusually high basal systolic murmur. In addition there is a narrow vascular pedicle on the plain chest film without any dilatation of the ascending aorta. External recordings of the carotid and brachial pulses may be helpful. The systolic ejection time is prolonged when there is significant obstruction, as in aortic valve stenosis, and the pulse contours show a difference in the upstroke time between the right and left sides. These findings, in a patient with evidence of left ventricular outflow obstruction, show that further investigation by left heart catheterization and angiography is necessary.

Supravalvar aortic stenosis has a diverse ætiology, and a clinical classification is suggested.

We are grateful to Dr. S. Walker of The Chromosome Unit, Liverpool Radium Institute, for several chromosome studies on Case 2. 


\section{REFERENCES}

Archer, R. S. (1878). Note on a congenital band stretching across the origin of the aorta. Dublin J. med. Sci., 65, 405.

Beuren, A. J., Apitz, J., and Harmjanz, D. (1962). Supravalvular aortic stenosis in association with mental retardation and a certain facial appearance. Circulation, 26, 1235.

- Schulze, C., Eberle, P., Harmjanz, D., and Apitz, J. (1964). The syndrome of supravalvular aortic stenosis, peripheral pulmonary stenosis, mental retardation and similar facial appearance. Amer. J. Cardiol., 13, 471 .

Black, J. A., and Bonham Carter, R. E. (1963). Association between aortic stenosis and facies of severe infantile hypercalcæmia. Lancet, 2, 745.

Brockenbrough, E. C., and Braunwald, E. (1960). A new technic for left ventricular angiocardiography and transseptal left heart catheterization. Amer. J. Cardiol., 6, 1062.

Brody, H. (1942). Congenital cord across the orifice of the aortic valve. J. techn. Meth., 22, 110.

Burry, A. F. (1958). Supra-aortic stenosis associated with Marfan's syndrome. Brit. Heart J., $20,143$.

Cheu, S., Fiese, M., and Hatayama, E. (1957). Supra-aortic stenosis. Amer. J. clin. Path., 28, 293.

Cope, C. (1959). Technique for transseptal catheterization of the left atrium: Preliminary report. J. thorac. Surg., 37, 482.

De Grouchy, J., and Emerit, I. (1963). Chromosome studies in patients with supravalvular aortic stenosis. Lancet, $2,789$.

Denie, J. J., and Verheugt, A. P. (1958). Supravalvular aortic stenosis. Circulation, 18, 902.

Dotter, C. T., Bristow, J. D., Menashe, V. D., Starr, A., and Griswold, H. E. (1961). Stenosis of left ventricular outflow tract. Circulation, 23, 823 .

Eberle, P., and Beuren, A. J. (1963). Chromosome studies in patients with supravalvular aortic stenosis. Lancet, 2, 438 .

Epstein, E. J., and Coulshed, N. (1964). Assessment of aortic stenosis from the external carotid pulse wave. Brit. Heart J., 26, 84.

Fletcher, R. F. (1957). A case of osteosclerosis with hypercalcæmia and renal failure. Arch. Dis. Childh., 32, 245.

Franch, R. H., and Oran, E. (1963). Asymmetric arm and neck pulses: A clue to supravalvular aortic stenosis. Circulation, 28, 722. (Abstracts Amer. Heart Ass. 36th Scientific Sessions.)

Hancock, E. W. (1961). Differentiation of valvar, subvalvar and supravalvar aortic stenosis. Guy's Hosp. Rep., 110, 1 .

Joseph, M. C., Polani, P. E., and Gold, R. G. (1963). Chromosome studies in patients with supravalvular aortic stenosis. Lancet, $2,788$.

Lamy, M., de Grouchy, J., and Schweisguth, O. (1957). Genetic and non-genetic factors in ætiology of congenital heart disease: a study of 1188 cases. Amer. J. hum. Genet., 9, 17.

Lev, M. (1953). Autopsy Diagnosis of Congenitally Malformed Hearts. Charles C. Thomas, Springfield, Illinois.

Lurie, P. R., and Mendelbaum, I. (1963). Mechanism of brachial pulse asymmetry in congenital aortic stenotic lesions. Circulation, 28, 760. (Abstracts Amer. Heart Ass. 36th Scientific Sessions.)

Mencarelli, L. (1930). Stenosi supravalvolare aortica ad anello. Arch. ital. Anat. Istol. Pat., 1, 829.

Morrow, A. G., Waldhausen, J. A., Peters, R. L., Bloodwell, R. D., and Braunwald, E. (1959). 'Supravalvular aortic stenosis. Clinical, hemodynamic and pathologic investigations. Circulation, 20, 1003.

Palmer, C. G. (1963). Chromosome studies in patients with supravalvular aortic stenosis. Lancet, 2, 788.

- Lurie, P. R., Merritt, A. D., and Petry, E. L. (1963). Supravalvar aortic stenosis: Genetic and chromosomal studies. Abstracts: Conference American Eugenics Society, New York, July, 1963.

Rashkind, W. J., Golinko, R., and Arcasoy, M. (1961). Cardiac findings in idiopathic hypercalcemia of infancy. J. Pediat., 58, 464.

Ross, J., Braunwald, E., and Morrow, A. G. (1960). Left heart catheterization by the transseptal route. A description of the technic and its applications. Circulation, 22, 927.

Sissman, N. J., Neill, C. A., Spencer, F. C., and Taussig, H. B. (1959). Congenital aortic stenosis. Circulation, 19, 458.

Williams, J. C. P., Barratt-Boyes, B. G., and Lowe, J. B. (1961). Supravalvular aortic stenosis. Circulation, $24,1311$.

Wooley, C. F., Hosier, D. M., Booth, R. W., Molnar, W., Sirak, H. D., and Ryan, J. M. (1961). Supravalvular aortic stenosis. Clinical experiences with four patients including familial occurrence. Amer. J. Med., 31, 717.

,-- , Meckstroth, C. V., Sirak, H. D., and Molnar, W. (1963). Supravalvular aortic stenosis: An emerging clinical entity. Circulation, 28, 827. (Abstracts Amer. Heart Ass. 36th Scientific Sessions.) 